\title{
MATHEMATICAL MODELLING OF SCALING IN A RESERVOIR WHICH CONTAINS IMPERMEABLE LAYERS
}

P. Bedrikovetsky
SPE/State U. of North Fluminense LENEP/UENF
F. Rosario
SPE/Pctrobras/UN-BC
M. Bezerra
M. Silva
SPE/Petrobras/ Cenpes Research Centre
Petrobras/UN-BC
R. Lopes Jr.
Statc U. of North Fluminense LENEP/UENF
Rodovia Amaral Peixoto, km 164
27973-030, Imboassica, Macać-RJ, Brazil

\section{ABSTRACT}

Several different scenario of injected and reservoir water mixing have been proposed mixing at high velocity near to injectors, mixing at low velocity inside reservoirs, mixing by diffusion via boundaries of layers with different permeabilities, mixing of injected, connate and aquifer waters at high velocity near to producers. Just the latter mechanism results in the accumulation of formation damage, while other mechanisms cause precipitation near to moving concentration front. In the current paper a new mechanism of oilfield scaling by diffusion of Barium from impermeable layer into the reservoir is proposed. The mechanism results in accumulation of precipitant and of formation damage. Viscous dominant regime of waterflooding takes place in the majority of oil fields. The Welge's method allows calculating the permeability distribution from water cut history. The proposed extension to Welge's method determines the partition of permeable layers in a reservoir from tracer concentration in production wells. Knowledge of this partition is important for modelling of oilfield scaling accounting for Barium supply from impermeable layers.

\section{INTRODUCTION}

Scaling is a chronicle disaster for waterflooding - it happens in the majority of reservoirs where an injected water is incompatible with the "reservoir" water, and the necessary precautions have not been taken ${ }^{1,2}$. Scaling results in injection and production well impairment, in plugging the tubing, etc.

The reason for damage is precipitation of salts in a solid state after mixing the injection and reservoir water $\mathrm{s}^{1,3,4}$. Solids can easily plug flow channels and significantly reduce the permeability.

The solid precipitation and consequent formation damage has been the subject of numerous studies over the past three decades. Kinetics of chemical reactions with formation of Barium and Strontium sulphates and of calcite have been studied in details for different baro-thermal reservoir conditions under different chemical ambients of the system 'water-rockoil ${ }^{-5-7}$.

The prediction of well behaviour under the scaling can be done by a mathematical modelling of flow in porous media with chemical reactions ${ }^{8-10}$. The modelling of flow with chemical reactions which cause scaling have been studied by numerous authors ${ }^{1,11}$. Many of these works assume local thermodynamic equilibrium, while others assume partial equilibrium ${ }^{12,13}$. The non-equilibrium scaling processes have been modelled using kinctics of chemical reactions $s^{5,6}$, and the equations have been

Engenharia Térmica, Ediçāo Especial, n. 2, 2002 p. 15-21 solved using finite-difference methods ${ }^{1,11}$

Am important advance have been done in the recent work $^{12}$, where the semi-analytic model for flow with scaling chemical reactions have been developed. In this work, the radial flow near to injection wells is considered.

The reservoir scaling can follow different scenario. The salt precipitation happen near to injection wells, in situ in the reservoir and near to production wells ${ }^{1}$. A sea water, produced water or water from a natural sources can be injected and interact with an aquifer water or connate water ${ }^{1}$.

The above-mentioned mechanisms, with the exception of the near-producer-scaling, do not cause the formation damage accumulation. The chemical reaction happens in the mixture zone near to the concentration front, so the precipitation zone moves along with the concentration front.

In the current paper the scenario of Ba supply into the $\mathrm{SO}_{4}$-rich injected sea water from impermeable layers is proposed. The phenomenon allows to explain the accumulation of Barium sulphate and of formation damage behind the injected sea water front. The method for determination of the impermeable layer fraction uses concentration of a salt in production wells. The concentration of a salt chosen should be different in the injection and formation waters.

The method is a generalisation of the common Welge's method $^{8}$ for determination of permeability distribution from water cut history during a viscous dominant waterflooding. The 
upscaled model for tracer concentration at viscous dominant waterflooding neglects the cross layer diffusion ${ }^{9,14}$. The proposed method for determination of impermeable layer fraction is based on the Welge's technique as applied for the upscaled saturation-concentration model ${ }^{14}$.

\section{FORMULATION OF THE PROBLEM}

The net pay is an important characteristic of oil reservoir The logging shows that up to a half of a reservoir thickness is filled by mobile oil while the other layers do not produce oil. Low permeable layers outside the net pay are saturated mostly by water, often oil saturation in impermeable layers is negligibly small.

This low permeable/impermeable layers are not involved nor in the pressure depletion neither in waterflooding of oil reservoirs.

Despite the low porosity of impermeable layers, highly saturated water can accumulate significant amount of aqueous components per unit of the reservoir thickness. The diffusion via the boundary between permeable and impermeable layers results in mass transfer by these components.

Losses of injected tracers and polymers into impermeable layers have been reported in the literature ${ }^{15}$.

The precipitation of Barium sulphate during the displacement of injected water by sea water happens in the neighbourhood of the concentration front, and the precipitation regime moves together with the concentration front. The precipitation in a given reservoir point does not happen after passing of this point by the mixing zone. The diffusion of $\mathrm{Ba}$ from impermeable layers into the reservoir net pay happens during and after the mixture zone movement, so the precipitant accumulates in each point of the reservoir. It could result in significant increase of formation damage caused by oilfield scaling.

\section{DETERMINATION OF IMPERMEABLE LAYER PARTITION}

We propose the method for determination of impermeable layer partition from tracer concentration in production wells At the absence of impermeable layers, the produced concentration history is determined by permeability profile and by lateral diffusion. At the presence of impermeable layers, some tracer diffuses from the reservoir into impermeable layers. Losses of tracer from the reservoir into impermeable layers cause reduction in production concentration.

The claret can be proposed as a natural tracer during the injection sea water into offshore fields. Usually chlorite concentration in formation water highly exceeds chlorite concentration in the sea.

\section{MATHEMATICAL MODEL FOR WATERFLOODING BY TRACED WATER}

The mathematical model for a viscous dominant waterflooding of the reservoir by traced water is based on the following assumptions ${ }^{8,9}$ :

- Incompressible oil and water phases
- Piston like displacement in each layer

- Viscous pressure drop along the reservoir highly exceeds capillary pressure and the hydrostatic pressure difference over the reservoir thickness

- Pressure gradient is constant over the vertical

- The layers are filled by injecting water in other of the permeability reduction

- There is no diffusion across the layers at the scale of a reservoir thickness

- Each layer $\Delta z$ contains the $\alpha$-th part of permeable layers and $1-\alpha$-th part of impermeable layers.

- The diffusion at the layer scale instantly equalises concentrations in permeable and impermeable parts of the layer.

The reference time of the diffusion across the reservoi equals $H^{2} / D_{z}$. The hypothesis that the vertical diffusion can be neglected at the reservoir thickness scale, means that the time $H^{2} / D$ highly exceeds the period of one pore volume injection $\phi L U U^{2}$. For the reservoir with $H=33 \mathrm{~m}, D_{z}=10^{-8} \mathrm{~m}^{2} / \mathrm{s}, \phi=0.2, L=500$ $\mathrm{m}, U=10^{-6} \mathrm{~m} / \mathrm{s}$, the vertical diffusion time equals $10^{11} \mathrm{~s}$, and the 1 p.v.i. period equals $10^{-6} \mathrm{~s}$. So, the vertical diffusion can be neglected on the reservoir thickness scale.

If the thickness of permeable and impermeable layers alteration $l$ is $0.1 \mathrm{~m}$, the diffusion time on the layer scale equals $l^{2} / D_{z}=10^{6} \mathrm{~s}$, which can be neglected if compared with the period of 1 p.v.i,, and one can assume that tracer concentrations in permeable and in impermeable layers are equal.

If the thickness of permeable and impermeable layers alteration $l$ is $1 \mathrm{~m}$, the diffusion time on the layer scale equals $l^{2} /$ $D_{z}=10^{8} \mathrm{~s}$, which has the same order of magnitude as the period of 1 p.v.i. In this case, concentrations in both parts are not equal, from one hand side, but the tracer transfer by diffusion in impermeable layers cannot be neglected, from another hand side. In this case, the proposed method will give low estimate of the partition $\alpha(z)$.

The mathematical model for the traced waterflood assumes the following schemas of the saturation of porous media by phases (Fig.1) and of the displacement and concentration fronts propagation in layer cake reservoir (Fig.3). Water and oil fill the $\alpha$-th part of the reservoir, the $I-\alpha$-th part is filled by water only. Porosities of the parts are $\phi$ and $\phi_{i}$ respectively (Fig.1).

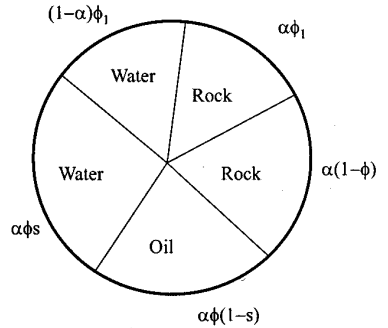

Fig. 1 - Water saturation in permeable and impcrmeable rocks

Engenharia Térmica, Edição Especial, n. 2, 2002, p. 15-21 
Water propagates faster in highly permeable layers, so the front of piston like displacement $h=h(x, t)$ declines along the vertical altogether with the depth permeability increase. Water saturations ahead and behind the displacement front are $s_{w i}$ and $I-s_{o r}$ respectively.

The tracer front $g=g(x, t)$ lags behind the displacement front due to tracer dissolution in the connate water even at the absence of impermeable layers ${ }^{1.8,9.14}$, where $\alpha=1: h(x, t)>g(x, t)$. The presence of impermeable layers increases the gap between the displacement and concentration fronts (Fig. 2).

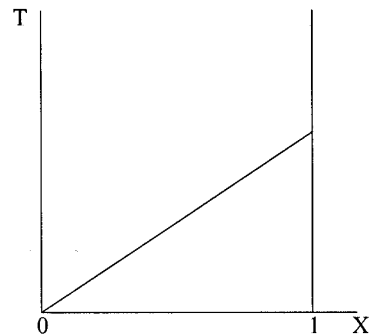

Fig.2. The solution S,C is constant along the lines $X=\xi T$, where $\xi=$ const

The mathematical model for viscous dominant waterflooding incorporates Darcy's law for oil and water (A-3), (A-4) and the above mentioned assumptions. Averaging of fluxes across the vertical (A-5), (A-6) allows the introduction of fractional flow (A-7). Finally the average water saturation dynamics is described by the water mass balance equation (A11). This equation is the Dietz model for viscous dominant waterflooding 8 .

The mass balance equation for tracer (A-12) account for dissolution of tracer in the water, which saturates permeable and impermeable parts of porous media.

\section{ANALYTICAL 1-D MODEL FOR TRACED WATERFLOODING}

This model is described in works ${ }^{9,14}$. The solution is self-similar and depends on the velocity of saturation and concentration value propagation X/T (Appendix B). The shape of concentration and displacement fronts follows Fig. 3. The concentration front lags behind the displacement fronts.

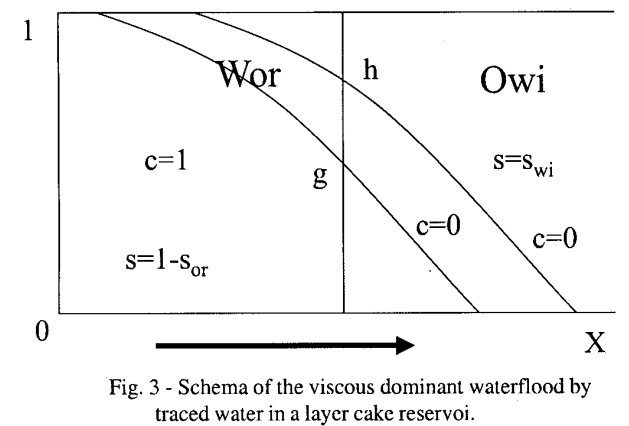

Engenharia Térmica, Edição Especial, n. 2, 2002 p. 15-21

\section{TWO INVERSE PROBLEMS OF RESERVOIR CHARACTERISATION}

There is an important observation about the relationship between the direct and inverse problems ${ }^{9}$. Any analytical solution of the system of mathematical physics equations is a consequence of the symmetry, and the symmetry always results in the reduction of the problem dimension. For these cases, the associated inverse problems are well posed, i.e. they always allow for the solution and the solution is unique and stable with respect to small perturbations of the data.

The traced waterflooding data allows for two inverse problems (Appendix C): determination of fractional flow function $F(S)$ from the water cut history, and determination of permeable layer partition $\alpha(z)$ from the outlet concentration history.

\section{DETERMINATION OF THE FRACTIONAL FLOW FUNCTION}

The problem for determination of the fractional flow function from water cut history (Appendix $\mathrm{C}$ ) is solved by a common Welge's method ${ }^{8}$. The method do not require the analytical solution of the direct problem, it is based solemnly on the fact of the self-similarity of the direct problem solution.

Integration of the Buckley-Leverett equation over the triangle on the plane X,T (Fig. 2) results in the expression (C-2). This expression allows calculating average water saturation in permeable layers in the reservoir outlet cross section. Plotting these values together with the water cut values on the plane $(S, F)$ results in the fractional flow curve.

\section{DETERMINATION OF THE $\alpha(Z)$ FUNCTION}

The solution of this inverse problem is given by a generalised Welge's method (Appendix C). The formulation of the inverse problem is as following: determine $\alpha(z)$ from the concentration of tracer at the outlet. Integration of the tracer mass balance equation (A-12) over the triangle on the $(X, T)$ plane allows calculating an average concentration in the outlet reservoir cross section (C-5). Altogether with the saturation value $S(1, T)$ each permits to calculate the tracer fractional flow $G(S, C)$ along the self-similar path of the direct problem solution

The formulae (A-1), (A-2), (C-5) and (C-6) allow for simultaneous determination of the permeability and permeable layer partition distributions.

\section{EXAMPLES}

The reservoir A (Brazil) is submitted to waterflooding. Presently BSW values rise up to $0.75-0.85$. It is an offshore field, so the inter well distances are high. Permeability is also high. The pressure drop between injectors and producers highly exceeds hydrostatic drop over the reservoir thickness and the capillary pressure. So, the waterflooding is dominated by viscosity.

Water cut history for three wells is given in Figs. 4,5,6. The chlorite concentration in production water is given also.

The permeability distribution profiles as obtained from water cut history are given in Figs. 7,8,9 respectively. 


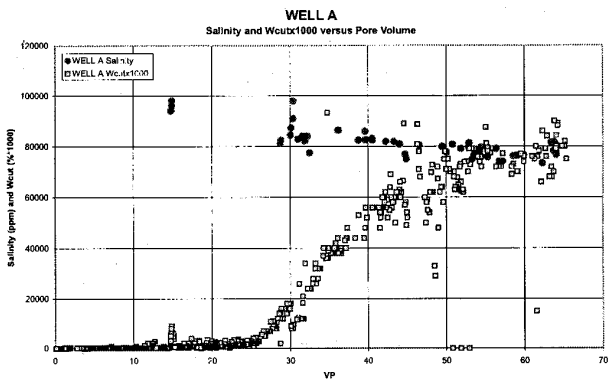

Fig. 4 - Water cut and clorite concentration in well A.

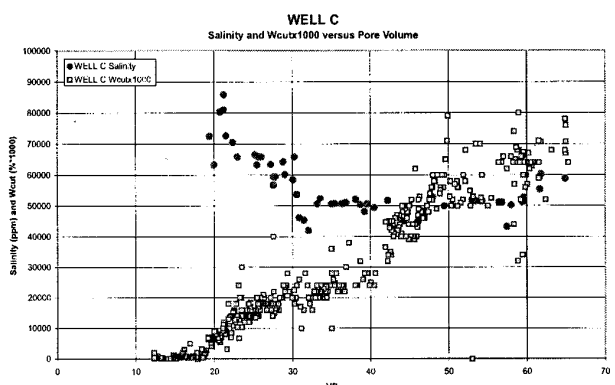

Fig. 6 - Water cut and clorite concentration in well C.

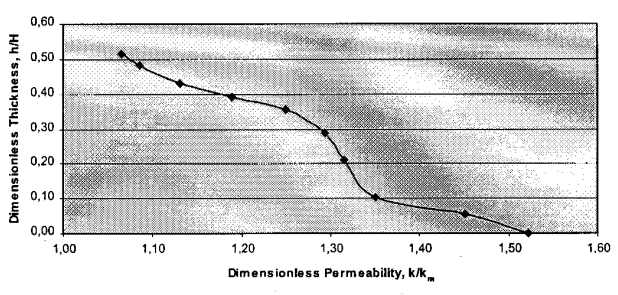

Fig. 8 - Permeability profilc $\mathrm{k}(\mathrm{z})$ as obtained from BSWhistory of well B.

It is important to point out that, despite the inverse problem can be solved for any concentration history, the formulation of the model (A-10), (A-11) presumes that the outlet concentration decreases with time. Nevertheless, the concentration in Well B is not monotonic. It means that some other sources of the reservoir water are not accounted in the model.

The permeability alteration length $\mathbf{l}$ for the reservoir $\mathrm{A}$ is about $1 \mathrm{~m}$. So, the reference time of the diffusion across the layer has the same order of magnitude as the period of 1 p.vi. So, the method for permeable layer fraction determination gives just a low estimate for $\alpha z$ ).

Both wells $\mathrm{A}$ and $\mathrm{C}$ exhibit the concentration point "clouds" which can be differently approximated by monotonic curves $G(I, T)$. The function $\alpha(z)$ decreases monotonically for both wells. It decreases from 0.85 at $z=0$ to 0.78 at $z=1$ for well $\mathrm{A}$, and from 0.88 to 0.82 for well $\mathrm{C}$.

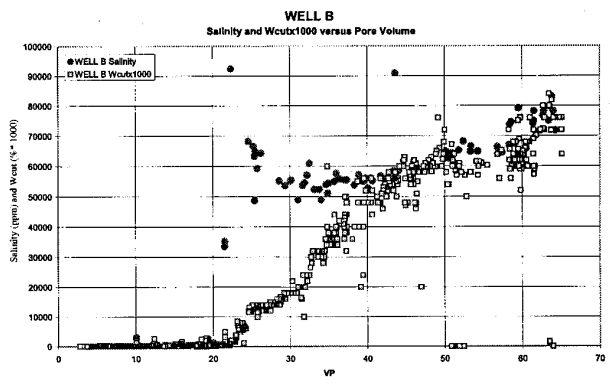

Fig. 5 - Water cut and clorite c.oncentration in well B.

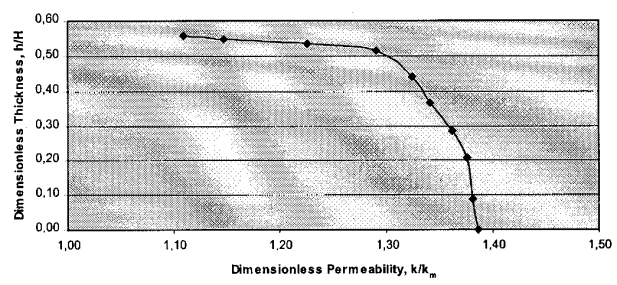

Fig. 7 - Permeability distribution near to well A as obtaneid from water cut history.

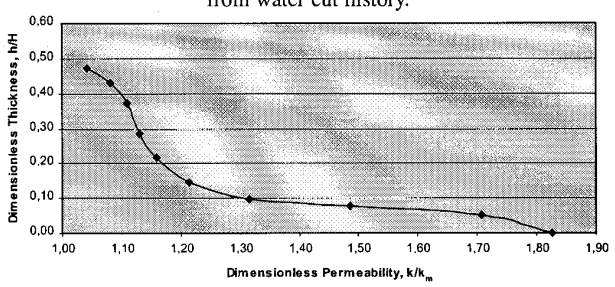

Fig. 9 - Permeability distribution near to well $\mathrm{C}$ as obtained from water cut history.

\section{CONCLUSIONS}

The qualitative analyses of scaling in heterogeneous reservoirs and mathematical modelling of mass transfer accounting for impermeable layers allows to make the following conclusions:

1. The mixing mechanism between the injected and formation waters by the Barium supply into the reservoir from impermeable layers during waterflooding is proposed. The mixing of injected water and water from impermeable layers happens behind the concentration front and results in the accumulation of precipitant and of formation damage.

2. The mathematical model for oil field scaling accounting for Barium diffusion from impermeable layers contains the parameter of the volumetric fraction of permeable layers in the reservoir.

Engenharia Térmica, Edição Especial, n. 2, 2002, p. 15-21 
3. A method for determination of the volumetric partition of permeable layers in a reservoir from concentration of tracer in the produced water is developed. The method is based on the exact solution of the inverse problem.

\section{ACKNOWLEDGEMENT}

The authors thank Petrobras for permission to publish the results. The project was sponsored by Finep-CTPETRO nos. 65.99.0468.00 and 65.00.0424.00.

Many thanks are due to Prof. Dan Marchesin (IMPA Brazil), Dr. A.L. Serra and A. G. Siqueira (Petrobras) and Eurico Altoé (UENF/Lenep) for discussions on the mathematical modelling. Authors thank Dr. E. Mackay and Prof. K. Sorbie from Herriot Watt University for fruitful discussions on the reservoir physics.

\section{NOMENCLATURE}

$\mathrm{t}=$ Time, $\mathrm{t}, \mathrm{s}$

$\mathrm{T}=$ dimensionless time in pore volumes

$\mathrm{x}=$ linear distance, $\mathrm{L}, \mathrm{m}$
$\mathrm{X}=$ dimensionless distance

$\mathrm{L}=$ Distance between injector and producers, $\mathrm{L}, \mathrm{m}$

$\mathrm{S}=$ average water saturation in permeable layers

$\mathrm{C}=$ Overall average water saturation

$\mathrm{k}=$ permeability, $\mathrm{L}^{2}$, md

$\mathrm{k}_{0}=$ average permeability, $\mathrm{L}^{2}$, md

$\lambda=$ filtration coefficiente

$\mathrm{U}=$ total flow velocity, $\mathrm{L} / \mathrm{t}, \mathrm{m} / \mathrm{s}$

$\mathrm{p}=$ pressure, $\mathrm{M} / \mathrm{Lt}$, bar

$\phi=$ porosity of permeable layers

$\phi_{1}=$ porosity of permeable layers

$\mathrm{H}=$ reservoir thickness

$\mathrm{D}_{\mathrm{z}}=$ vertical diffusion coefficient, $\mathrm{Lt}^{2}, \mathrm{~m} / \mathrm{s}^{2}$

$\mathrm{l}=$ permeability alteration distance, $\mathrm{L}, \mathrm{m}$

$\alpha=$ fraction of permeable layers

$\alpha=$ average fraction of permeable layers

$\mathrm{H}=$ vertical position of water-oil conatct

$\mathrm{G}=$ dimesnionless vertical position of concentration front

$\mathrm{Z}=$ dimensionless vertical coordinate

$\mathrm{G}=$ fractional flows for traced water

$\mathrm{M}=$ mobility ratio

$\mathrm{U}_{\mathrm{C}}=$ overall flux of traced water, $\mathrm{L} / \mathrm{T}, \mathrm{m} / \mathrm{s}$

\section{APPENDIX A. A 1-D MODEL FOR WATERFLOODING WITH TRACER}

Each horizontal reservoir cross section $\Delta z$ consists of permeable layers that occupy $\alpha$-th fraction of the thickness (net pay) and of impermeable layers. The permeable part is saturated by water and oil, oil saturation in impermeable layers is neglected (Fig. 1). Average water saturation $S$ in permeable part of a vertical cross section is

$$
\begin{aligned}
& \phi \alpha_{0} \mathbf{s}(\mathbf{x}, \mathbf{t})=\phi\left(1-\mathbf{s}_{\text {or }}\right) \alpha_{0} \int_{0}^{\mathbf{h}} \alpha(\mathbf{z}) \mathrm{dz} \\
& +\phi \mathbf{s}_{w i} \alpha_{0} \int_{\mathbf{h}}^{1} \alpha(\mathbf{z}) \mathbf{d z}
\end{aligned}
$$

The formula can be simplified:

$\phi \alpha_{0} \mathbf{s}(\mathbf{x}, \mathbf{t})=\phi\left(1-\mathbf{s}_{\text {or }}-\mathbf{s}_{w i}\right) \alpha_{0} \int_{0}^{h} \alpha(z) d z$

$+\phi \mathbf{s}_{\text {wi }} \alpha_{0}$

The average water saturation $C$ in the overall cross section, including both impermeable and permeable parts, equals

$$
\begin{aligned}
\phi \alpha_{0} \mathbf{C}(\mathbf{x}, \mathbf{t})= & \phi\left(1-\mathbf{s}_{o r}\right) \alpha_{0} \int_{0}^{\mathrm{g}} \alpha(\mathbf{z}) \mathbf{d z} \\
& +\phi_{1} \int_{0}^{\mathrm{g}}\left(\mathbf{1}-\alpha_{0} \alpha(\mathbf{z})\right) \mathbf{d z}
\end{aligned}
$$

Gathering the terms in front of integral, we obtain:

$$
\phi \alpha_{0} \mathbf{C}(\mathbf{x}, \mathbf{t})=\left(\phi\left(1-\mathbf{s}_{\text {or }}\right) \alpha_{0}-\phi_{1} \alpha_{0}\right) \int_{0}^{g} \alpha(z) d z
$$

$+\phi_{1} \mathbf{g}$

The horizontal velocities of water and oil are

$\mathbf{u}_{w}=-\frac{\mathbf{k}_{0} \mathbf{k}(\mathbf{z}) \mathbf{k}_{\mathrm{rwor}}}{\mu_{w}} \frac{\partial \mathbf{p}}{\partial \mathbf{x}}$

$\mathbf{u}_{0}=-\frac{\mathbf{k}_{\mathbf{0}} \mathbf{k}(\mathbf{z}) \mathbf{k}_{\text {rowi }}}{\mu_{\mathrm{o}}} \frac{\partial \mathbf{p}}{\partial \mathbf{x}}$

Averaging phase velocities (A-3), (A-4) over the vertical coordinate and accounting for viscous dominant regime hypothesis results in expressions for overall water and oil fluxes

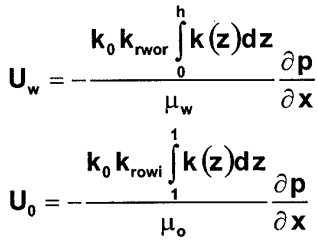
fluxes:

It allows introducing fractional flows for overall phase

$\mathbf{U}_{\mathrm{w}}=\mathrm{FU}, \quad \mathbf{U}_{\mathrm{o}}=(1-\mathrm{F}) \mathrm{U}$

$\mathbf{U}=\mathbf{U}_{\mathbf{w}}+\mathbf{U}_{\mathbf{o}}$ 

(A-6)

The expression for fractional flow follows from (A-5)

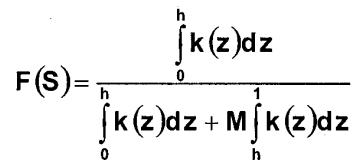

The fractional flow for the traced water is:

$$
\mathbf{G}(\mathbf{S}, \mathbf{C})=\frac{\mathbf{U}_{\mathbf{c}}}{\mathbf{U}}=
$$

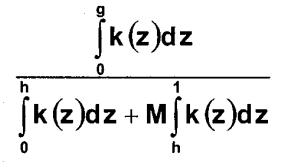

Let us introduce dimensionless coordinate and time

$$
\mathbf{X}=\frac{\mathbf{x}}{\mathbf{L}} ; \quad \mathbf{T}=\frac{\mathbf{U} \mathbf{t}}{\alpha \phi \mathbf{L}}
$$

Mass balance equations for water and for tracer (traced water) are as following:

$$
\begin{aligned}
& \frac{\partial \mathbf{S}}{\partial \mathbf{T}}+\frac{\partial \mathbf{F}(\mathbf{S})}{\partial \mathbf{X}}=\mathbf{0} \\
& \frac{\partial \mathbf{C}}{\partial \mathbf{T}}+\frac{\partial \mathbf{G}(\mathbf{S}, \mathbf{C})}{\partial \mathbf{X}}=\mathbf{0}
\end{aligned}
$$

\section{APPENDIX B. SOLUTION FOR 1-D WATERFLOODING WITH TRACER}

The initial conditions for the system (A-11), (A-12) correspond to initial water saturation and absence of tracer in the reservoir before the flooding

$$
\begin{aligned}
& \mathrm{T}=0: \mathrm{S}=\mathrm{s}_{\mathrm{wi}}, \quad \mathrm{C}=0 \\
& \mathrm{~T}=0: \mathrm{h}=0, \quad \mathrm{~g}=0
\end{aligned}
$$

The boundary conditions correspond to full saturation of the inlet cross section by traced water

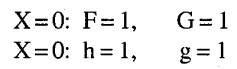

The solution of the problem is self-similar, it depends on the ratio $X / T$. It was derived in the paper ${ }^{14}$, and the complete derivations are presented in the monograph ${ }^{9}$.
The saturation problem (A-11), (B-1), (B-3) can be separated from the whole problem (A-11)-(B-4). The solution $S(X / T)$ is given by a rarefaction wave which is expressed by the explicit formula ${ }^{8}$. It corresponds to the piston like front $h(X, T)$ of the displacement of oil by water (Fig. 3).

The concentration solution $C(X / T)$ is given by the ordinary differential equation ${ }^{9,14}$. It corresponds to the concentration front $g(X, T)$ which separates waters with and without tracer behind the waterflood front (Fig. 3). There is always a delay of tracer arrival to production wells, i.e. tracer front lags behind the waterflood front, $g(X, T)<h(X, T)$. The higher the fraction of impermeable layers $\alpha$, the larger is the delay.

\section{APPENDIX C. THE WELGE'S METHOD FOR INVERSE PROBLEM SOLUTION}

The first inverse problem is the determination of fractional flow function $F(S)$ from water cut history $F(1, T)$ The second inverse problem is the determination of fractional flow for traced water $G(S, C)$ and of permeable layer fraction distribution $a(z)$ and of permeability distribution $k(z)$ from the concentration history $G(I, T)$.

Integration of water balance equation (A-11) over the triangle $(0,0)->(1,0)->(1, T)->(0,0)$ in the plane $(X, T)$ (Fig. 2$)$ gives:

$$
-\mathbf{S}_{\mathrm{wi}}+\int_{0}^{T} \mathbf{F}\left(1, \mathbf{T}^{\prime}\right) \mathbf{d} \mathbf{T}^{\prime}+\mathbf{S}(1, \mathbf{T})-
$$

$-F(1, T) T=0$

It allows calculating the water saturation in permeable layers in the reservoir outlet:

$$
\mathbf{S}(1, T)=\mathbf{s}_{\mathrm{wi}}-\int_{0}^{T} \mathbf{F}\left(1, \mathbf{T}^{\prime}\right) \mathbf{d} \mathbf{T}^{\prime}+\mathbf{F}(1, \mathrm{~T}) \mathbf{T} \quad(\mathrm{C}-2)
$$

The formula $(\mathrm{C}-2)$ presents the solution in the form $S=S(F)$. The inverse function $F=F(S)$ presents the solution of the first inverse problem. The set of couples $(S(I, T), F(l, T))$ forms a curve $F(S)$ in the plane $(S, F)$, that is the fractional flow curve for the viscous dominant waterflooding.

Formula for the fractional flow (A-8) allows deriving the following expression:

$$
\int_{0}^{h} k(z) d z=\frac{M F}{1-F+M F}
$$

Integration of traced water balance equation $(A-12)$ over the triangle $(0,0)->(I, 0)->(I, T)->(0,0)$ in the plane $(X, T)$ (Fig. 2) gives:

$$
\int_{0}^{T} \mathbf{G}\left(1, \mathbf{T}^{\prime}\right) \mathbf{d} \mathbf{T}^{\prime}+\mathbf{C}(1, \mathbf{T})-\mathbf{G}(\mathbf{1}, \mathbf{T}) \mathbf{T}=\mathbf{0} \quad(\mathrm{C}-4)
$$

It allows calculating the traced water saturation in permeable layers in the reservoir outlet:

$$
C(1, T)=-\int_{0}^{T} \mathbf{G}\left(1, \mathbf{T}^{\prime}\right) \mathbf{d} \mathbf{T}^{\prime}+\mathbf{G}(\mathbf{1}, \mathbf{T}) \mathbf{T}
$$

The formula (C-5) presents the solution in the form $C=C(G)$ along the solution $S(X / T), C(X / T)$. The inverse

Engenharia Térmica, Edição Especial, n. 2, 2002, p. 15-21 
function $G=G(S, C)$ presents the solution of the second inverse problem along the path $S(X / T), C(X / T)$.

Formulae for the fractional flows of traced and nontraced waters (A-8), (A-9) allows to derive the following expression:

$$
\int_{0}^{g} k(z) d z=\frac{M G}{1-F+M F}
$$

The formula (C-6) allows the calculation of the highs of concentration front in the reservoir outlet $g(T)$. Substitution of this dependence into the expression for traced water saturation (A-2) and using the values $C(1, T)$ allows to calculate the distribution of permeable layer fraction $\alpha(z)$.

\section{APPENDIX D. THE 1-D MODEL FOR BARIUM SULPHATE SCALING}

The model consists of 3 equations for Ba mass balance in pcrmeable layer, for $\mathrm{SO}_{4}$ mass balance in permeable layer and for Ba mass balance in impermeable layer. The term of Ba mass transfer between permeable and impermeable layers is proportional to the $\mathrm{Ba}$ concentration difference in permeable and impermeable layers. The proportionality coefficient equals $\mathrm{D}_{z} \mathrm{~L}(1-\alpha) \phi_{1} / \alpha \phi \mathrm{Ul}^{2}$ for the system as transformed to the dimensionless coordinates (A-10).

At the impermeable layer absence, where $\alpha=1$, , the mass transfer term equals zero.

\section{REFERENCES}

1. Sorbie, K. S. and Mackay, E. J., 2000, Mixing of Injected, Connate and Aquifer Brines in Waterflooding and its Relevance to Oilfield Scaling, Journ. Petr. Sci. Eng., 27, 85-106.

2. Rosario, F. F., Bezerra, M. C., 2001, Scale Potential of a Deep Water Field - Water Characterisation and Scaling Assessment, SPE paper 68332 presented at 2001 SPE Third International Symposium on Oilfield Scaling, Aberdeen, UK, 30-31 January.

3. Allaga, D.A., Wu, G., Sharma, M.M, Lake, L.W., 1992 Barium and Calcium Sulphate Precipitation and Migration inside Sandpacks, SPE FE, March.

4. Dunn, K., Daniel,E., Shuler, P., et. al., 1991, Mechanisms of Precipitation and Dissolution of Barite: A Morphology Approach, J. of Coll and Interface Sci., 214, 427-437.

5. Todd, A.C. and Yuan, M.D., 1992, Barium and Strontium Sulphate Solid-Solution Scale Formation at Elevated Temperatures, SPE Production Engineering, February, 85-92.

6. Wat, R.M.S., Sorbie, K.S., Todd, A.C., Ping Chen and Ping Jiang, 1992, Kinctics of BaSO Crystal Growth and Effect in Formation Damage, SPE 23814 presented at the SPE Intl Symp on Formation Damage Control held in Lafayette, Louisiana February 26-27.

7. Monnin, C., 1999, A Thermodynamic model for the Solubility of Barite and Celestite in Electrolyte Solutions and Sea Water to $200^{\circ} \mathrm{C}$ to $1 \mathrm{kbar}$, Chemical Geology, $153,187-209$ 8. Lake, L. W. , 1989, Enhanced Oil Recovery, Prentice
Hall, Engelwood Cliffs, NY.

9. Bedrikovetsky, P. G., 1994, Mathematical Theory of Oil and Gas Recovery, Kluwer Academic Publishers, London/ Boston.

10. Green, D. W. and Willhite, G. P., 1998, Enhanced Oil Recovery, SPE Textbook Series.

11. Rocha, A., Frydman, M., Fontoura, S., Rosario, F. Bezerra, M., 2001, Numerical Modelling of Salt Precipitation during Produced Water Reinjection, SPE 68336 presented at 2001 SPE Third International Symposium on Oilfield Scaling, Aberdeen, UK, 30-31 January.

12. Araque-Martinez, A., Lake, L. W., 1999, A Simplified Approach to Geochemical Modelling and its Effect on Well Impairment, SPE paper 56678 presented at the 1999 SPE Annual Technical Conference and Exhibition held in Houston, TX, 3-6 October.

13. Steefel, C. and Van Cappellen, P., 1990, A New Kinetic Approach to Modelling Water-Rock Interaction: The Role of Nucleation and Ostwald Ripening., Geochim. Cosmochim. Acta, July, V. 54, 2657-2677.

14. Bedrikovetsky P.G. Tracer Analyses in Stratified Reservoirs (Determination of Permeabilities Profile). SPE Conference EUROPE'C, Cannes, France, 16-18 November 1992 CRCPress. 